working elements in a muscle, an undamped elastic element and an apparently damped element, both working in series, and it is thought that the sarcolemma and the muscular substance within it acting in the way described by the author represent respectively these two elements.

\section{Ophthalmic Folk-Lore}

Accordrng to Dr. J. D. Rolleston (Brit. J. Ophthal., November), no branch of medicine has a more abundant supply of folk-lore than diseases of the eye. Although ophthalmology reached a high degree of develop. ment at an early stage of its history, rational views concerning its etiology and treatment were for a long time associated with the grossest errors and absurdities. Pliny's "Natural History", which is one of the chief storehouses of folk medicine, contains numerous references to the eye, which he describes as the most precious part of the human body. Pliny, however, was a credulous bookworm and not a man of science, and many of the remedies which he mentions were not only disgusting but also injurious. Of subsequent writings dealing with the folk-lore of eye diseases Dr. Rolleston mentions Cockayne's "Leechdoms, Wortconning and Starcraft", Moncrief's "Poor Man's Physician" and Wesley's "Primitive Physick"'.

Among popular superstitions connected with the eye, by far the most important, owing to its great antiquity, its persistence in many parts of the world and its effects, is the doctrine of the 'evil eye'. The earliest document concerning it dates back to the seventh century B.c., and is drawn up in two languages, Assyrian and Accadian. There are numerous references to it in the Bible, Talmud, Koran and the works of classical antiquity. Although belief in the 'evil eye' is not so prevalent as it was, it is by no means extinct. In Europe it is most frequently encountered in countries along the Mediterranean, particularly Italy and, most of all, Naples. In India and China, as well as among the Arabs and Turks, the 'evil eye' is particularly dreaded owing to the harm it may inflict on horses and camels. Possession of the 'evil eye' has been attributed to numerous animals, though not so frequently as to man, and even some inanimate objects, such as peacock's feathers and the photographic camera. Apart from the 'evil eye', popular superstitions connected with the eye, though numerous, are comparatively insignificant and innocuous. In conclusion, the article deals with the chief ocular diseases in which folk-lore remedies are employed, namely, 'sore eyes', styes, foreign bodies and cataract.

\section{Classification and Nomenclature of Cancer}

THE September issue of the Boletin de la Oficina Sanitaria Panamericana contains an article by Dr. Conrado Zuckermann, director of the anti-cancer campaign of the Department of Public Health in Mexico, who states that this department seeks the co-operation of the medical profession and the public. Literature on cancer has been prepared for both these groups; a cancer dispensary is being organized, and a histological service is already open to medical men, to which they may send specimens for examination together with the clinical history. For the sake of standardization of terminology, Dr. Zuckermann has drawn up a classification of new growths according as they are epithelial, mesenchymato-connective, muscular, nervous and gonocytic. As regards nomenclature, the suifix -oma is applied to benign growths and -blastoma to malignant tumours.

\section{Health of Iceland}

According to the October issue of the Journal of the Royal Institute of Public Health and Hygiene, Iceland is in the happy position of placing old age at the head of its list of causes of death. Its latest report shows that old age is responsible for 15 per cent of all deaths, with cancer second, 14 per cent, pneumonia, heart disease and apoplexy third, just over 10 per cent, and tuberculosis 8 per cent. The vital statistics are birth-rate $19 \cdot 4$, death-rate $11 \cdot 7$, infant mortality $37 \cdot 3$, and mortality $2 \cdot 1$. Baths in private houses in Iceland are the exception, their place being taken by the big public baths which are supplied with hot water from the natural hot springs. The climate makes it difficult to grow vegetables out of doors, but the profusion of natural hot water renders possible the economical production of hothouse flowers and fruit.

\section{Yellow Fever in Brazil}

ON the occasion of the first celebration of the Panamerican Health Day on December 2, 1941, Dr. Waldemar Antunes gave a survey of the yellow fever situation in Brazil (Bol. Of. San. Panamericana, 21, $758 ; 1942)$. The special control measures applied to all inhabited zones have resulted in the disappearance of yellow fever from the country since 1934. The discovery, however, in 1932 of a jungle form of the disease has necessitated the employment of coordinated measures by every American country in the fight against the Stegomyia mosquito. Owing to the work carried out in Brazil by the Yellow Fever Service, of which Dr. Antunes is the director, no Stegomyia have been found for several years in the States of Maranhão, Espirito Santo, Goiaz, Paraná, and Santa Catarina; 2,084,839 persons have been inoculated against jungle yellow fever by the National Yellow Fever Service.

\section{Swedish Archæology}

According to the September issue of the AngloSwedish Review a find has recently been made near Shövde in western Sweden consisting of a bronze cauldron and a single-edge iron sword, the head of a javelin and a fine shield boss. This is the first complete set of arms found in western Sweden that can be dated to the centuries just before the birth of Christ. A closer examination of the site of the discovery resulted in the discovery of no less than twenty-two tombs. Another discovery has been recently made in Landa, also in West Sweden, namely, three pieces covered with gold plates dating from about A.D. 500. The total number of gold pieces of this kind, of which several have runic inscriptions, is about 175 in Sweden and 550 in the whole of Scandinavia.

\section{Announcements}

The Goethe Prize of the city of Frankfurt-a.M. for this year has been awarded to Prof. Richard Kuhn, director of the Kaiser Wilhelm Institute for Medical Research at Heidelberg.

THE William Osler Medal of the American Society of the History of Medicine has been awarded to John T. Barrett, of the University of Boston. 